\title{
新科學一天文生物學
}

\section{吉霍失著 㲀永本譯}

1945年在阿拉木圖(Aлma-Ara)誕生了一門科

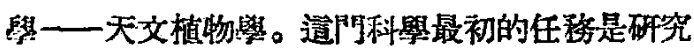
滈仙上及北極附近植物的光學上的性質。這對於 瞭解氣倿嚴寒的火星上的植物情形是很必要的。 在1946年中期,許多更進一步的研究指出了： 天交植物學在造方面已積累了許多非常有邀的事 凟。因此在1947年十一月，在哈薩克共和國科學院 主庶團的領蔀下，成立了天交植物學研究所。但現

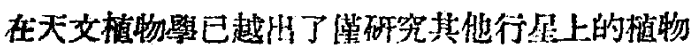

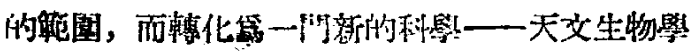
了。

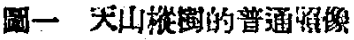

\section{一 植物對低罝的適簿}

在1948年年底，天文植物祭研究所的科學工

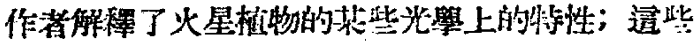
特性在過去都是難於理解的。

地球上的植物都具伤反射太陽光兂中的紅外 光的特性。但火星上的植物則浔有造程現像。地球

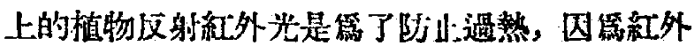
光所会的熱約占陽光總熟的一半。在火星上，情形 便兩樣了。它的天氣是非常貿寒的，因此紅外光 對於植物的生活也就成筑不可缺少的東西。所以 火星上的植物是完全吸收紅外光的。-

由此我們便可以這樣推想：地球上的常䊅植

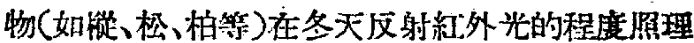

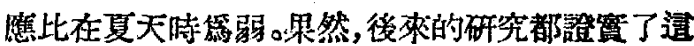
㑬推論。高山上的植物也有這程特性。但是，不管 怎菉，我們的常綠植物即使在冬天也不能完全㫨 收紅外光。從這裹,可以得出結論：即使在冬天不 完全吸收紅外光，它們本身的温度也已足够。它們 很頑强而不怕嚴寒。

在製造食物方面，碳和氧的化合物一二二氧

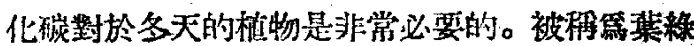

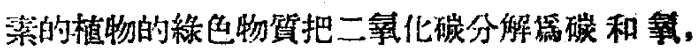

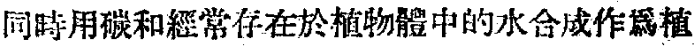

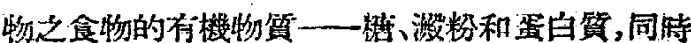

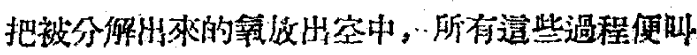
做光合作用。在十九世紀的下但世紀著名的俄国

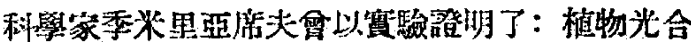
作用的發生，主要靠吸收光䍀中一小部份的紅光; 道小部份紅光叫做棐綵素的吸收帶。

這犦說來，如果在火星上有類似地球做物的

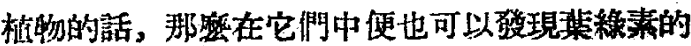
旪收帶。但是培多而且多年的對於火星的觀察都 沟有發現這㮈的吸收帶。因此外国的學者們便作 H了這菉的結諭：如果在火星上有植物的話，至多

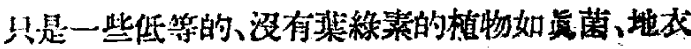
等面已。

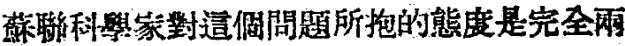

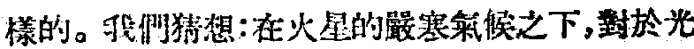
合作用來說，槛物只吸收紅光中的一小部份是不 


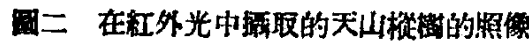

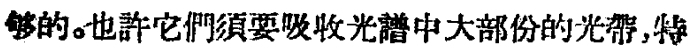

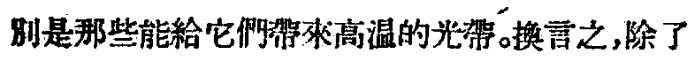
紅外光外，它們還須要收收紅、登黄、黃及称色的

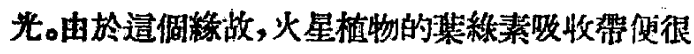
䙾，因此我們健看不到它。(渠程素吸收帶呈照色， 聥宽時往往伩看不見。一譯者註)

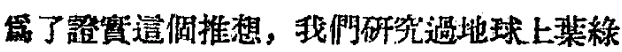
素的喛收帶; 研筦的地點不僅在暖和的天氮下，也 在铰寒的天氣下，甚至在山上和北極附近。很快地

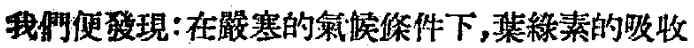

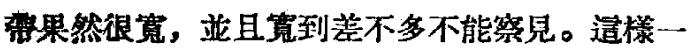
來,那就很明䫏：在火星上能够俻在高等的、具有

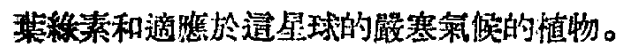

紅、橙黃、黄和絑色光線之被大量吸收世說朋 了第甚㦄火星上的植物生長地帶會現出淺藍色、

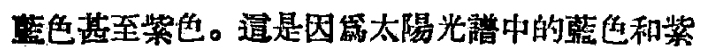
色光線的温度很低，因此火星植物便反射它們，美 不多把它們罍作繁用的東西一榜。

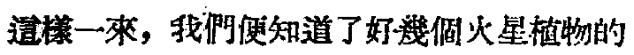
特性; 激了寈些特性, 火星上的植物便道應了嚴祭 的氣俊條件。當然，除了遭些特性，它們還具有有

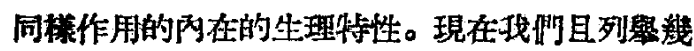
倜植物䝵應周園保件的例子。

B.B. 阿列興教授指出：在西伯利亞北岸，匙

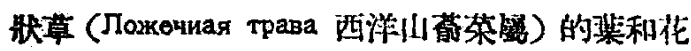

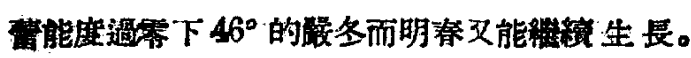

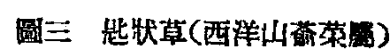

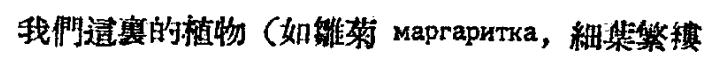
мокрица, 三色堇 анютины глазки) 也是追棌過冬

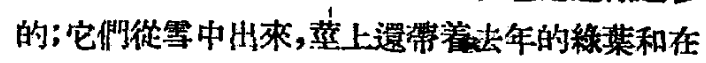

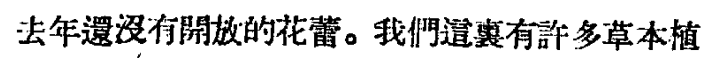
物在冬季不落渠, 有如常释植物 (如黄花川芝旅 зөлечук, 吹洲細辛 копытень)。

植物的最低生長温度是很有趣的; 大多數植 物的最低生長温度在零度以上，但阿隬埤斯以系 的植物(如山1櫻草 сольданелга, 番紅花 шафран等) 


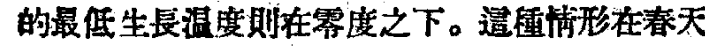
。開花的植物中(如白嘼翁) анемона-ветреница, 紫 革屬 ховлатка, 飛莨草 чистяк) 也何以看到。它 們在冬季也能在雪下生長; 並且由於逭㑑原因,它 們往往在早春便開始開花。

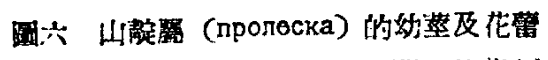

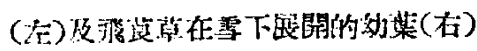

我洲耐以推想: 這些植物是冰河時代的遺物, 它們把它們所持有的生長特性一值保留到現在。

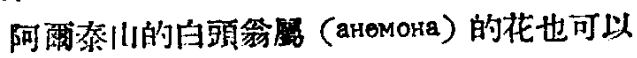

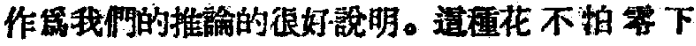
$5^{\circ}-10^{\circ}$ 的初霜: 在四月初旬, 它能在舒利恶 (山ория) 山地上(西部西伯利亞)從還涩有溶化的 厚迋10-15公尺的雪中生長出來。這種植物的花 呈瀎藍色,韮子帶紫色。

\section{二 植物對高溫的適應}

在1948年八月我們發現了花在光譜上的紅光 和紅外光 (инфракрасные лучи) 中有自己放射的 現象。经了做這些研究，我们會利用過特别製造 的盗光性箱 (фпуоресцентный ящик)。它是一储無 底的箱，箱的上角稍斜。在科角上铰了一個可以

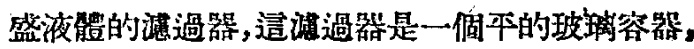
其中盛涩了硫酸銅溶液; 這種溶液能完全吸收光 譜中近邊際的紅光 (即最長的可見光, 波長䄪 $7 \times 10^{-5}$ 厘米一一譯者註)及紅外光。

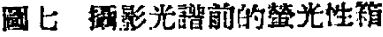

用那籍子把被研究的植物蓝上，再把蚾有清 過器的一面朝向太陽, 因此植物便僅能受到透過

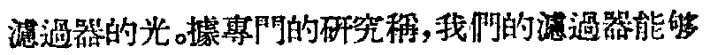
透過光譜中緊接着的紫外光、紫色、藍色、淺藍色、 綠色、黄色和橙黄色的光，並且能完芼败收約光及

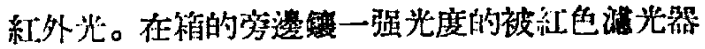

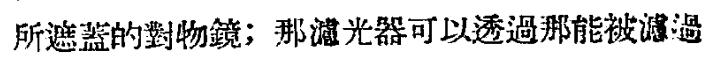

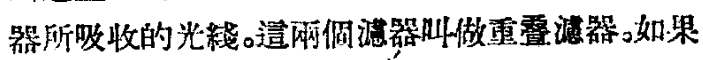

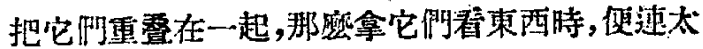
陽也看不見。再把强光度的對物鏡與裝有感光底 片的照相機漸在一起。這感光底片能感受光敦中 一切的光, 從紫外光開始到紅光葚至和外光篇止。

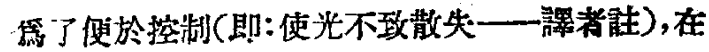
植物周園裝置了石霄圈。

在箱了，中的植物和石管圈侐能受到那不能到 


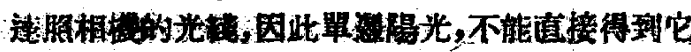

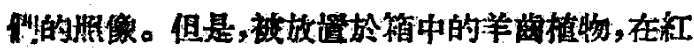
业中却給了我椚一個很令人满意的照像（造次㦄 月了不能感受紅外光的感光底片)。至於石情圈, 它僅被羊醨植物自己放出來的光所照耀着; 特别

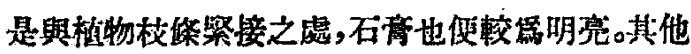
被我們研究迻的植物和花也登生與造相類似的情 移，不同點只在於它們的自己放射力有大有小而 E。

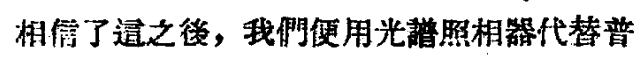

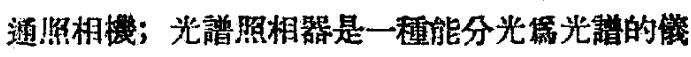
器。造棈一來, 我們便能更準確地研究郱些在其中 能碚生植物自己放射現缘的光。道使我們能確定

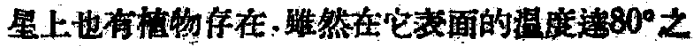

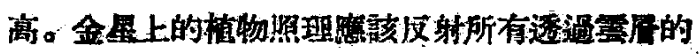
隄光，所以它阿也焦該是白色。但是，因的牠阿 還理㗹放射紅光和與紅光相隣的隥黄色和黄色的 光，因此金星植物的基本領色也許是白色、责色或 紅色。逼栐看來，根據上远材料，我們可以這樣推 想:枋物不僅在火星上存在，也在金星上存在。同 時還會很自然地生出造硾想法：在造雨湖行星上 可能有高等野物存在; 而在火星, 世許甚至有有理 性的生物存在。

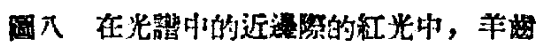 植物自己放射的掅形。}

椥物自故光的能與照射它們的光的能之關保。通

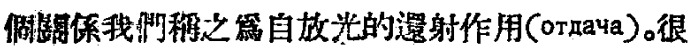
块地找們双發現了: 随着空氮温度的增高，自放光 的澴射作用也隨着加强。第了證管這倜發現，我們 叉在 $-40^{\circ}-20^{\circ}$ 的範園內短察了同溙的植物。例 如: 搠的自己放射力在道種情形下便燴加了 40倍。 係似的現像說明：自己故射可以使植物能够 叒於過熱之害,造梯,我們便猛現了植物的第二種 特性，這種特性使它能調造從隄光中所得到的温 度。如上所连，使植物能名於過熱之害的第一種特 性就是反射紅外光。

在植物中郋现的新特性使我們可以假定在金
A九

1. 晹光

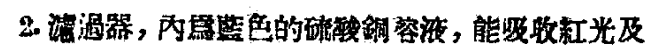

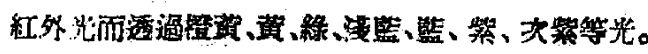

3. 植物

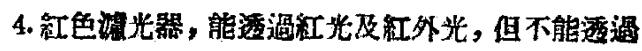

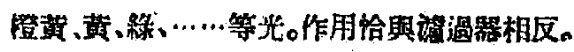

5. 柴物等(䀦透鏡)。

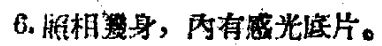

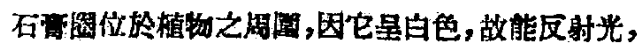
优光栈免於散头。

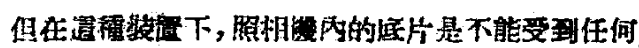

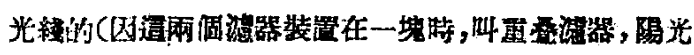

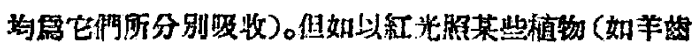

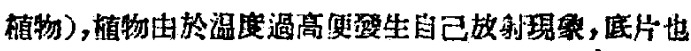

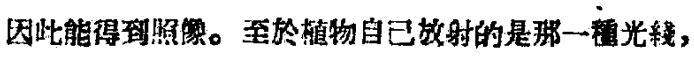

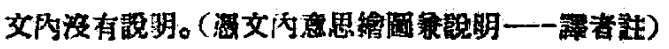




\section{三 低等生物缽環境條件的適磨}

B.И. 維爾紑特斯基院上在他所落的“生物環

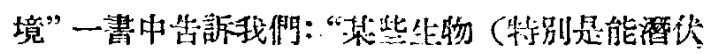
生命的, 如菌類的芽孢)可以涊受的最高温度涬

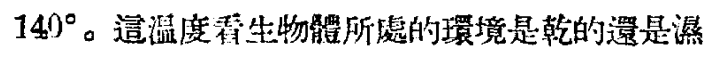
的而變化。”

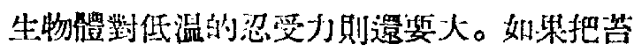
類、地衣、海草坊於 $-190^{\circ}$ 的液態空策中数星期, 然後再把它們放於㠇水中，於是硬化了的原生筫

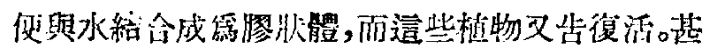
至在真空乾燥的環境中經過了分年湴且接着双放

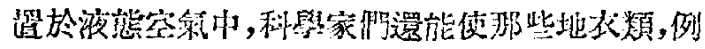

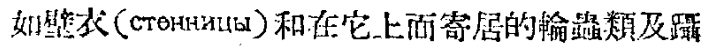

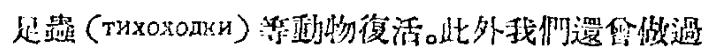

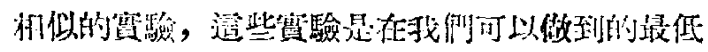

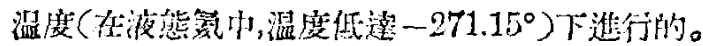

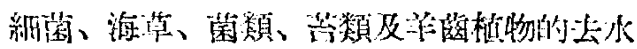

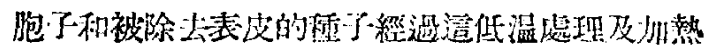

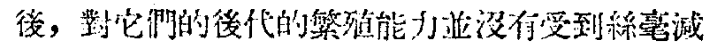
弱。

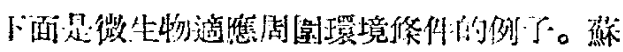

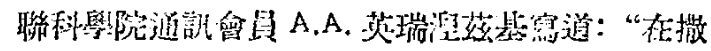

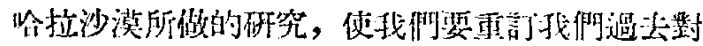
“生命的䢬界”所下的絬論。沙漠亚不是死象沉沉

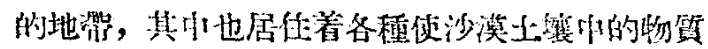
進行很環的微生物。”

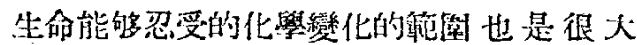
的。C.H，維恠格拉特斯基的研究指出，生命能離 開有機環境而生存於純粰偘機的環境中。孢子和 種子(生命的潛伏形式)可以在完全涩待巢體和水

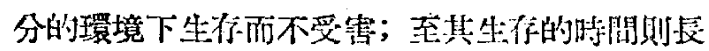
短不等。並且在生存的時閔中，生命的各種形式能 你在於各程各漛的化學環境中。新所週知的,有些

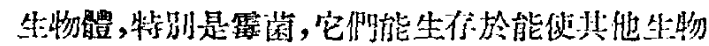

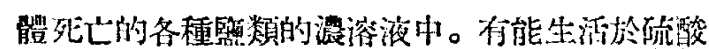

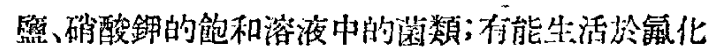

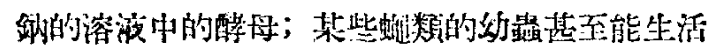
於 $10 \%$ 的印醮溶液中。此外還有能生活於是永的 瀄溶液中的細䒩。

\section{四 在大行星上可能有生命雄?}

入行星一一水星、土星、天王星和海王星與太

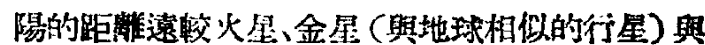
太陽的距離答大。因此在它們外颉上的温度也就

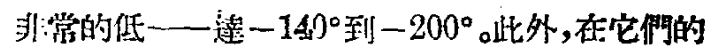

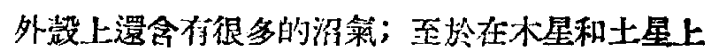
则存很多蝶氣狀的阿母尼亞。在道些行星的空策 中，高紫動物是不能够你在的。

但如湿我們想及上述的甚至能够生活於像甲 醛、是秉造些强烈的毒:物中的微生物時,我們便很 可以這傣推想：在這些行星上是十分可能存在那

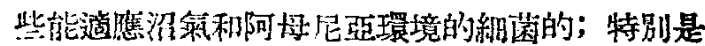

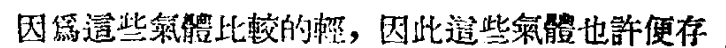
在於大行星空氣的上屡。

我們有光分理山相信：在這些大行星上的温 度必隨氣啳的下降而增高。在十九世紀的七十年 代け，木星上大紅斑點(遖径約等於地球的三倍)

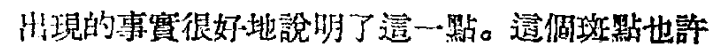
是該行星深陷部份的鉻化了的地方。踓然從那㭙 開始,這社斑點缏大大地縮小了，但是現在還可以 看得到。造就說明了: 在木星的深陷部份, 温度還

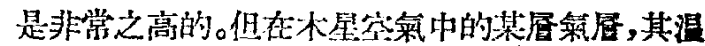
度應該比雾度稍高，因此在那襄細茼是完全能够 生存和繁殖的。

在大行星上，那些大量的沼氣和阿时尼亞到

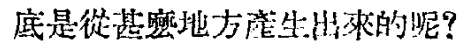

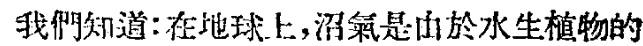

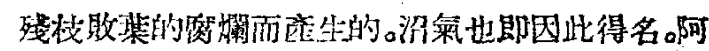

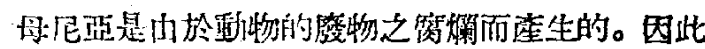

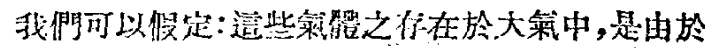

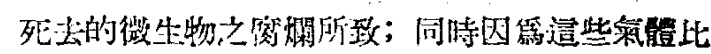

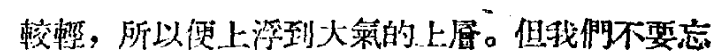
$了$ : 在地球、火星和金星的大秋中也有僌量不大的 沼氧呢。

因此，我們有根據來假定：且不說火星和金 星, 就是在其彵入行星上世有微生物的保在。

$$
\times \times x
$$

我㑚逜䇾諭交指出了：生命是非常堅忍和倔 强的現象。它能够你在於與地球完全不相同的儤 境中。

生命能㿟而且歪該不僅存在於太陽采的各行

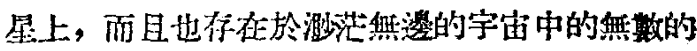
行星上。

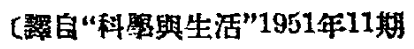
Г. А Тихов, Новая наука.]

\section{第四期}

科學通 報 